\title{
Effects of regular administration of red wine on testicular profile and body weight in adult male experimental model
}

\author{
Ubi Essien Isaac ${ }^{1}$, Kebe Edet Obeten ${ }^{1}$, Anozeng Oyono Igiri ${ }^{2}$ \\ ${ }^{I}$ Department of Human Anatomy and Forensic Science, Faculty of Basic Medical Sciences, Cross River University of Technology, Calabar, Nigeria \\ ${ }^{2}$ Department of Human Anatomy, College of Medical Sciences, University of Calabar, Calabar, Nigeria
}

Received: 2021-05-24.

Accepted: 2021-07-10

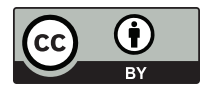

This work is licensed under a Creative Commons Attribution 4.0 International License

\section{J Clin Med Kaz 2021; 18(4):75-80}

Corresponding author:

Ubi Essien Isaac.

E-mail: isaacubireal@gmail.com; ORCID: 0000-0003-4577-6278

\begin{abstract}
Aim: The present study determined whether or not the regular intake of red wine causes any significant changes in testicular and body weight parameters, given the existing controversy over the effect of alcoholic beverages on health system.

Material and methods: Ten male albino Wistar rats -experimental model with average body weight of $140 \mathrm{~g}$ were divided into two groups, $A$ and $B,(n=5$ each). Group $A$ received distilled water being the control while group B was administered a single daily dose of $5 \mathrm{ml} / \mathrm{kg}$ body weight of red wine (Carlo Rossi) for 21 days. An electronic weighing scale (G\&G® Neuss, Germany) was used to take record of the initial and final body weights. The animals were anesthetized with isoflurane on the 22 nd day to enable collection of the testes which were also weighed and thereafter fixed in 10\% neutral formalin for routine histological studies. The analysis of variance was used with the 'R' software to analyze the statistical data, while $P<0.05$ was taken as the significant value.

Results: The micro-anatomical investigation revealed enhanced perfusion of the tissue and normal morphology of the seminiferous tubules with constituent spermatogenic cells at different stages of maturation. The biometric assessment of the organ (testis) weight showed no significant difference; whereas there was a statistically significant increase in the final body weight of the treated-experimental model when compared with the control.
\end{abstract}

Conclusion: The findings indicate that the intake of red wine at the investigated amount may maintain the integrity of the primary reproductive structure and lead to body weight gain in males.

Key words: red wine, testis, maintenance, body weight, increase

\section{Introduction}

Wine, generally, is an alcoholic drink or beverage consumed in many parts of the world for its biological roles, especially in curbing stress. Red-wine in particular is made from the juice of dark-coloured grapes by the introduction of yeasts to cause natural fermentation. It is composed mainly of water, carbohydrates, organic acids, minerals, alcohol, polyphenols and aromatics [1,2]. The application of yeast during the crushing process breaks down the sugars found in the grapes and converts them to alcohol [3], while its red-colored appearance often results from the presence of anthocyanin pigments in the skin of the grapes [4,5].
Over the years, red wine has become popular for its reported positive effect on oxidative stress and coronary heart disease [6]. Notwithstanding, findings have indicated that the causative role of alcohol in cardio-protection is not certain $[7,8]$. According to Hansel et al [9], such protection may be due to some confounders and misclassification, asserting that those who take alcoholic drink moderately display a more favorable clinical and biological profile consistent with lower cardiovascular risk as compared with non-drinkers and heavy drinkers. In vitro and in vivo studies have found that a certain amount of everyday wine consumption may prevent various chronic diseases. This attributes in part, to the polyphenolic contents of the 
wine which include resveratrol, anthocyanins, catechins and flavonoids that act as anti-oxidants $[1,10,11]$.

While alcohol itself is usually a major component of different types of wine, the controversy over the effect of its intake on health parameters still exists. For instance, metaanalyses have shown the self-reported consumption of one to three (i.e. about $10 \mathrm{~g}-30 \mathrm{~g}$ alcohol) standard drinks per day to be associated with a $20-25 \%$ reduction in the risk of cardiovascular diseases (CVD) [12-14]. This lower risk of CVD observed in moderate drinkers is often attributed to the beneficial effects of alcohol on plasma lipids and lipoprotein, implying that small to moderate amounts of alcohol are good for one's health [9]. However, alcohol is reported to be the fifth leading cause of death and disability accounting for about $4 \%$ mortality; and the harmful effects of its intake could result in conditions or diseases such as liver cirrhosis, injuries and cancers of the liver, colorectum, breast, and upper aero-digestive tract [15].

On being specific about the association between red wine and health, some reports have portrayed the effects of its components aside from excess alcohol consumption as healthdamaging, owing to pesticide and heavy metal content $[16,17]$. In contrast, other research findings point to the protective effects of red wine on health owing to the abundance of anti-oxidants $[18,19]$. Studies on the effect of regular drinking of different types of red wine on hormonal reproductive parameters in young adult male rats showed the product to influence the plasma levels and/ or concentration of follicle-stimulating hormone, testosterone, $17 \beta$-estradiol and prolactin. The observed effects were said to be dependent on the type and the dose of the red wine; while the chemical compounds or phenolics naturally occurring in red wines may modulate the effects of ethyl alcohol but also directly affect the male reproduction [20].

On highlighting the relationship of red wine consumption with weight, it has been reported that wine intake did not affect weight changes in patients with type 2 diabetes after initiating daily wine consumption for two years [21,22]. A cohort study in men also failed to show an association between wine intake and weight changes [23]. According to Maclnnis et al [24], middleaged participants of the Melbourne Collaborative Cohort study were less likely to have greater waist circumference and body weight when drinking low to moderate amounts of alcohol including wine. Also, mean BMI (basal mass index) was reportedly lower in people who drank alcohol and wine daily than those who consumed alcohol less frequently. However, for a given alcohol intake, wine consumption was inversely associated with BMI and waist circumference [25]. Moreover, a recent review which summarized the contribution of red wine consumption to human health, showed that its positive effects may fluctuate depending on the individual substances, positing that the topic requires further careful research [1].

Infertility is a devastating problem of human reproduction and male infertility is said to contribute to $50 \%$ of all infertility cases $[26,27]$. On the other hand, obesity rates are increasing rapidly worldwide, which is not only associated with an increased risk of developing reproductive disorders [28,29]. To further justify the present study, the polyphenols contained in wine have been said to contribute to its beneficial effects as indicated by an isolation study of resveratrol - a phenolic compound, in preventing cardiovascular diseases and protecting brain and nerve cells [10]. However, the said ingredient was reported to abrogate the reproductive capacity in male mice, as well as have a negative impact on the activities of antioxidant enzymes [30]. Hence, there is a crucial need for investigation into the biological effects of red wine on male reproductive and body weight parameters, in order to address the existing controversy.

\section{Materials and methods}

Ethical consideration: The required approval/consent to conduct this research was obtained from the Research and Ethics Committee of the Department of Anatomy, in the College of Medicine and Health Sciences of Abia State University, Nigeria. The guidelines for the use of experimental animals/or principles of laboratory animal care were carefully followed, as well as specific national laws.

Materials/Tools: These included cages for restraining the animals, electronic weighing scale ( $G \& G \AA)$, Neuss Germany) for checking the body weight, syringes for measuring the doses and administering the test substance, dissecting kit, chemical reagents including formalin, alcohol, xylene, hematoxylin and eosin, sample bottles, paraffin wax, embedding mould, rotary microtome, water bath, microscope glass slides and a light microscope.

Test substance: Carlo Rossi Wine (California Red) was purchased from a wine shop in Okigwe, Imo State - Nigeria, and used for the study. The wine's product details are as follows: Bottle size: $750 \mathrm{~mL}$; alcohol/volume: 11.5\%; made in United States of America (USA) by E. \& J. Gallo Winery; sugar content: $16 \mathrm{~g} / \mathrm{L}$; sweetness descriptor: D-dry; style: light-bodied and fruity; varietal: blend.

Experimental animals: Healthy male albino Wistar rats weighing between $108 \mathrm{~g}$ and $180 \mathrm{~g}$ were procured from a breeding facility and then confined in cages in the animal house of the College of Medicine, Abia State University, Uturu. They took water and were fed rat chow ad libitum during the period of the experiment.

Determination of dosage and administration of treatment: The initial body weight was taken prior to commencement of the experiment in order to determine the appropriate dose to be administered on each animal; while the formula: Dose $(\mathrm{mL}) \mathrm{x}$ Body Weight $(\mathrm{g}) \div 1000$ was used to calculate the dose for each animal. 10 male rats were separated into two groups designated $\mathrm{A}$ and $\mathrm{B}$, with each group consisting of five subjects. Group A received distilled water and served as the control while group B was administered $5 \mathrm{ml} / \mathrm{kg}$ body weight per day of the named red wine. Treatments were given once daily by oral route- gavage and lasted for 21 days. The animals were re-weighed on the 22nd day in order to take their final body weight. This was followed by anaesthetizing them using isoflurane to enable dissection and collection of the testes, which were also weighed and then processed for histological examination.

Histological processing: The testicular tissue samples were preserved in $10 \%$ formalin, dehydrated in ascending grades of alcohol and cleared with xylene. The cleared tissues were impregnated and infiltrated so as to remove the clearing agent. This was done by passing the samples through several changes of paraffin wax in a hot air oven for 30 minutes. The infiltrated tissue was embedded with molten paraffin wax in an embedding mould and allowed to harden. The tissues were mounted on wooden blocks and sectioned using a rotary microtome before being trimmed to obtain the cutting surface and then cut at 5 micron metres $(\mu \mathrm{m})$. Tissues were finally stained with hematoxylin and eosin dyes, mounted in distyrene plasticizer xylene (DPX) and allowed to dry. This was followed by micrography and examination of the samples under a microscope.

Statistical data analysis: The one-way analysis of variance (ANOVA) was used with the ' $R$ ' software to ascertain the changes in the body weight as well as the organ weight, 
between the experimental group and the control. The values were presented as mean \pm SEM and $\mathrm{P}<0.05$ was taken to be statistically significant.

\section{Results}

Physical Observation: There was a rapid increase in the appetite of the experimental subjects treated with red wine, as these were observed to consume more chow, and also exhibit much excitability than those in the control group.

Histological findings: The following micrographs are the result of testicular tissue specimen processing

Figure 1 - Photomicrograph of group A, control section of the testis $(x 400)(H / E)$ shows normal architecture with seminiferous tubules that contain sperm cells at different stages of development, and lined with Sertoli cells (SC) and interstitia cells of Leydig (ICL)

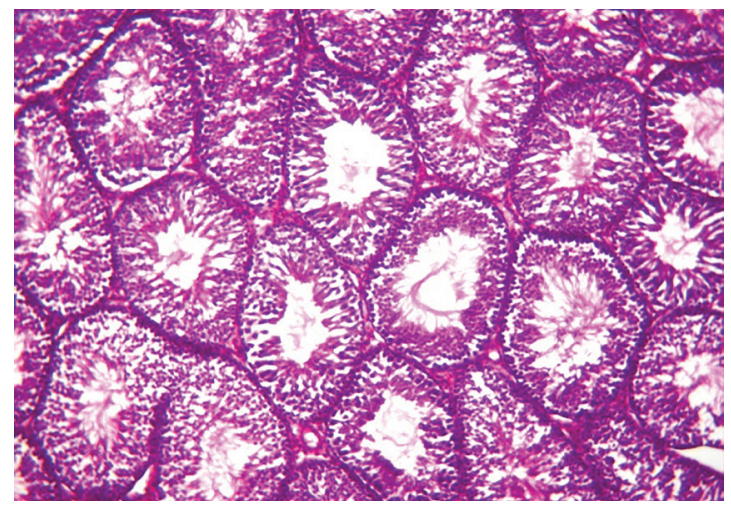

Figure 2 - Photomicrograph of group $B$, section of the testis administered with red wine $(\mathrm{X} 400)(\mathrm{H} / \mathrm{E})$ shows testicular tissue with enhanced perfusion (EP) and continuous maturation of the sperm cells (SC).

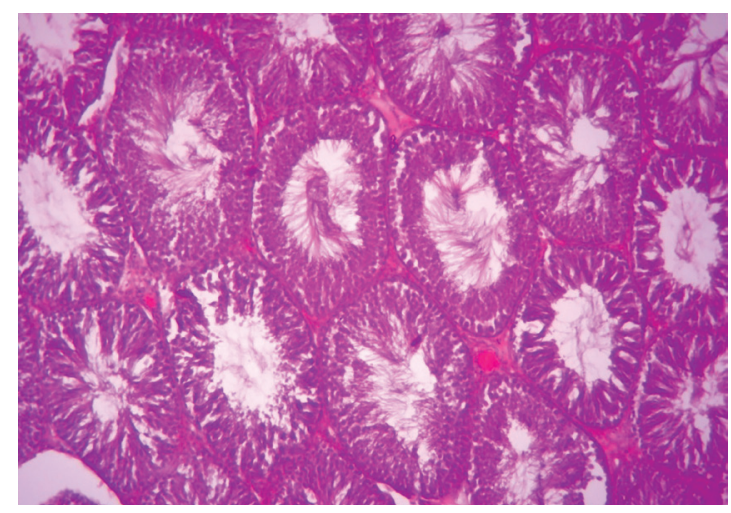

Table 1

Comparison of testes weight differences of the animals during the experimental period of 21 days.

\begin{tabular}{|l|l|l|l|l|l|}
\hline $\begin{array}{l}\text { Source of } \\
\text { variation }\end{array}$ & $\begin{array}{l}\text { Degree of } \\
\text { freedom } \\
\text { (D.f) }\end{array}$ & $\begin{array}{l}\text { Sum of } \\
\text { squares }\end{array}$ & $\begin{array}{l}\text { Mean } \\
\text { sum of } \\
\text { squares }\end{array}$ & $\begin{array}{l}\text { Frequency } \\
\text { distribution(fcal) }\end{array}$ & P-value \\
\hline $\begin{array}{l}\text { Between } \\
\text { treatment }\end{array}$ & 1 & 1.3682 & 0.45607 & 1.1754 & 0.357 \\
\hline $\begin{array}{l}\text { Within } \\
\text { treatment }\end{array}$ & 5 & 5.0443 & 0.38803 & & \\
\hline Total & $10(\mathrm{n})$ & & & & \\
\hline
\end{tabular}

Result shows that P-value is greater than (>) 0.05 , indicating no significant difference between the experimental group and the control.
Figure 3 - Turkey Multiple Comparison of Means (Box Plot) for testis-organ weight showing the mean levels at $3.3 \mathrm{~g}$ in group $\mathrm{A}$ and $4.0 \mathrm{~g}$ in group $\mathrm{B}$ as indicated by the bold transverse bands.

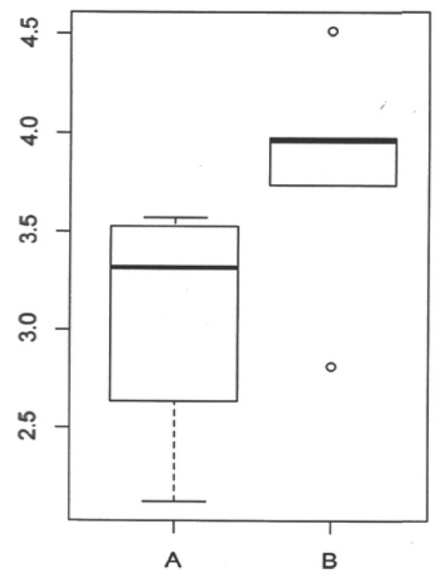

Figure 4 - 95\% family-wise confidence level for testes weight, shows no significant difference in mean levels due to intersection of the horizontal line (B-A) and the broken vertical line at 0.0 point.

$95 \%$ family- wise confidence level

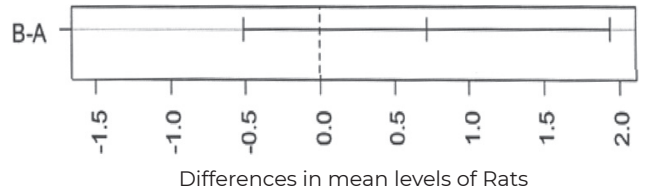

Table 2

Analysis of variance for final body weight

\begin{tabular}{|l|l|l|l|l|l|}
\hline $\begin{array}{l}\text { Source of } \\
\text { variation }\end{array}$ & $\begin{array}{l}\text { Degree of } \\
\text { freedom } \\
\text { (Df) }\end{array}$ & $\begin{array}{l}\text { Sum of } \\
\text { squares }\end{array}$ & $\begin{array}{l}\text { Mean } \\
\text { sum of } \\
\text { squares }\end{array}$ & $\begin{array}{l}\text { Frequency } \\
\text { distribution(fcal) }\end{array}$ & P-value \\
\hline $\begin{array}{l}\text { Between } \\
\text { treatment }\end{array}$ & 1 & 2364.8 & 1088.25 & 7.0446 & 0.004682 \\
\hline $\begin{array}{l}\text { Within } \\
\text { treatment }\end{array}$ & 5 & 2008.2 & 154.48 & & \\
\hline Total & $10(\mathrm{n})$ & & & & \\
\hline
\end{tabular}

Result shows P-value is less than $(<) 0.05$, implying there is a significant difference between the experimental group and the control.

Figure 5 - Turkey Multiple Comparison of Means (Box Plot) for the final body weight shows the mean levels at $135 \mathrm{~g}$ and $170 \mathrm{~g}$ in groups A and B respectively.

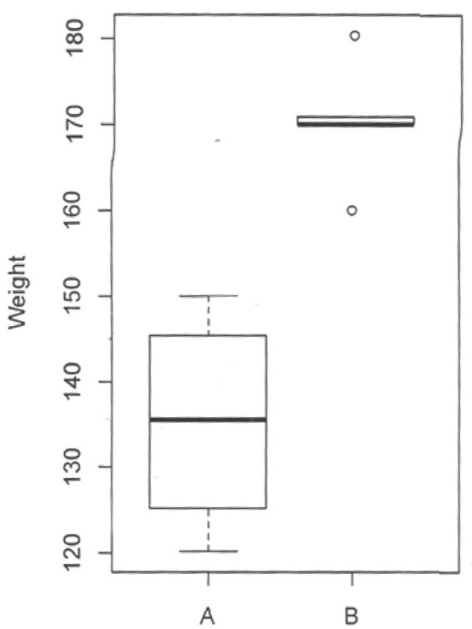


Figure 6 - 95\% family-wise confidence level for final body weight, indicates a significant difference between $A$ and $B$ due to non- intersection of the horizontal line (B-A) with the broken vertical line at 0 point.

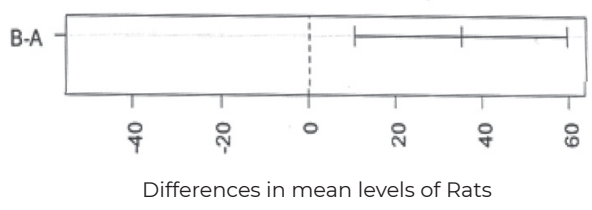

\section{Discussion}

Findings from the histological assessment of tissue samples of red wine did not show any adverse changes when compared with the control. The Photomicrograph of group $\mathrm{B}$, as presented in figure 2 showed enhanced perfusion of the testicular tissue, the presence of sustentacular -interstitial cells of Leydig and Sertoli's, as well as the continuous maturation of sperm-producing cells. These observed microscopic features were not significantly different in relation to figure 1 which represents a normal sample (i.e., from the distilled-water control group). While literature abounds on the positive role of red wine in cardio-protection, there is however, paucity of evidence on its effect on reproductive morphology. A report on the effect of regular drinking of different types of red wine on hormonal reproductive parameters and total antioxidant status in young adult male rats showed the product to influence the plasma levels or concentration of follicle-stimulating hormone, testosterone, $17 \beta$-estradiol and prolactin, as well as exert high antioxidant activity due to its content of polyphenolic compounds [20].

A summary of review of recent studies on the beneficial effects of moderate wine intake on human health has reported the valuable role, especially of red wine, in the prevention and treatment of chronic ailments such as cardiovascular disease, metabolic syndrome, cognitive decline, depression and cancer. These reported benefits were attributed to its phytochemical compounds, as highlighted by clinical trials where the effect of red wine has been compared to white wine, non- alcoholic wine, other alcoholic drinks and water. This implied that moderate wine intake at 1-2 glasses per day as part of the Mediterranean diet has been positively associated with human health promotion, diseases prevention and disease prognosis [31]. The consumption of red wine has also been indicated in decreasing the blood pressure of hypertensive patients [10].

On the other hand, the evidence deduced from the biometric studies using various analytic tools, showed the intake of red wine to significantly increase the body weight of the experimental animals when compared with that of the control. However, the increase in testis-organ weight was not statistically significant. The analysis of variance for the final body weight presented in table 2 gave a P-value of $0.004682(<0.05)$, while the turkey multiple comparison (Figure 5) showed a significant rise in the mean levels from $130 \mathrm{~g}$ in group A to $170 \mathrm{~g}$ in group B as indicated by the bold transverse (or horizontal) lines. Moreover, the $95 \%$ family wise confidence in figure 6 also indicates a significant difference as the horizontal line at B-A completely drifts away from the broken vertical midline at zero point. On the contrary, the analysis of variance for testicular-organ weight in table 1 , produced a P-value of $0.357(>0.05)$ indicating a nonsignificant rise or change. The turkey multiple comparison of means (Box Plot) from analysis of this organ weight presented in figure 3 , gave a mean value of $3.3 \mathrm{~g}$ for the control and $4.0 \mathrm{~g}$ for the red wine-treated group as clearly indicated by the bold transverse bands. The 95\% family-wise confidence level in figure 4, also did not show any significant increase in means as there was a clear intersection of the horizontal line (B-A) with the broken vertical line at 0.0 point.

Reports on the effect of wine drinking on body weight have been contradictory. This warrants the assessment of individual brands of alcoholic beverages so as not to only assume they all had the same effect, since other components beside the alcohol itself may have their roles to play depending on how a particular product is being used. Recent prospective studies suggest that light-to-moderate alcohol intake is not associated with weight gain or changes in waist circumference [24]. Heavy drinking, however, was reported as being more consistently associated with weight gain [32]. Furthermore, it has been reported that increases in alcohol intake patterns appear to promote weight gain [33].

Experimental evidence is also mixed and suggests that moderate intake of alcohol does not lead to weight gain over short follow-up periods. Many factors can explain the conflicting findings and a better characterization of individuals more likely to gain weight as a result of alcohol consumption is needed. Individuals who frequently dink moderate amounts of alcohol may enjoy a healthier lifestyle in general that may protect them from weight gain, while alcohol intake may be a risk factor for obesity in some individuals, likely based on a multitude of factors [34]. Also, Monteiro et al [35] reports that the ingestion of red wine may alter body weight gain, size of adipocyte, and the production of estrogen by adipose tissues, positing that some of these red wine effects are attributed to ethanol which is usually contained in the wine.

Studies conducted under controlled experimental conditions showed that moderate red wine consumption can prevent the increase of body weight by modulating energy intake in a dietinduced model of obesity [36]. The advantageous effects of wine have been largely attributed to different biological actions of its ingredients like polyphenols, whose activities are reported to include reduction of appetite, promotion of energy expenditure and prevention of energy storage [37]. While the appetite rate of the animals treated with red wine in the present study was observed to have largely increased; Cains et al [38] revealed how a widely consumed nutrient can paradoxically sustain starvation signals thus identified a biological factor required for appetite evoked by alcohol; suggesting that alcohol sustains fundamental appetite signals.

Although the result for body weight in the present study supports the alternative hypothesis (H1), it is also possible that other bioactive substances or ingredients in the wine aside from the alcohol could influence such outcome. This assertion may be drawn based on findings from a related research that investigated the effect of palm-wine (another popular brand of alcoholic drink) on body weight; which rather supported the null hypothesis (H0), as no significant change was observed [39]. Moreover, a study that tested the effect of red wine, beer and a soft drink served with a normal meal on ad libitum energy intake in non-obese men, showed that total energy intake was higher with red wine than with the soft drink and beer [40]. This evidence may be supported by the fact that energy often results from the breakdown of calories in the body. Thus, an abnormal increase in the amount of calories may cause energy to build up in the form of fat.

As a result of the controversy trailing the impact of alcohol, it is worth mentioning that the present research design 
took into account the standard- average dose of ethanol that could be consumed daily by individuals. Thus, given the product description, the red wine investigated contained $11.5 \%$ alcohol by volume (ABV). The formula used to work out how much alcohol that was being taken by the rats, in every $5 \mathrm{ml} / \mathrm{kg}$ was given as: amount of drink (i.e. volume of the container in litres) multiplied by the percent by volume of alcohol (i.e., ABV) multiplied by 0.789 (i.e. the density of ethanol at room temperature). Hence, a $750 \mathrm{ml}$ bottle of the wine was calculated as $0.75 \times 11.5 \times 0.789$ to yield 6.80 which is approximately 7 standard drinks. So, if the ethanolic quantity is estimated by dividing the total volume of the container into three portions (i.e. $750 \div 3$ ). This amounts to $250 \mathrm{ml}$, which falls within the recommendation of one to three (about $10 \mathrm{~g}-30 \mathrm{~g}$ alcohol) standard drinks per day.

\section{Conclusion}

Moderate and regular intake of red-wine can maintain the structural integrity of the male primary reproductive organ and result in body weight gain. However, we recommend that further studies be carried out in this regard to probe these findings or hypotheses, so as to enable a proper view in exploring the potentials of red wine product.

Disclosures: There is no conflict of interest for all authors.

Acknowledgements: The authors acknowledge the role of Emeritus Professor Francis C. Akpuaka in supervising the research and providing useful guidance during its conduct.

\section{Funding: None.}

\section{References}

1. Snopec L, Mlcek J, Sochorova L, Baron M, Hlavacova I, Jurikova T, et al. Contribution of red wine consumption to human health protection. Molecules. 2018; 23(7):1684. DOI: 10.3390/molecules23071684.

2. Macrae R, Robinson RK, Saddler MJ. Wine: In Encyclopaedia of Food Science and Technology 2nd ed. London: Harcourt Brace. 1993; 73-92.

3. Sharma AK, Singh PN, Sawant SD. Evaluation of fermentation efficiency of yeast strains and their effect on quality of young wines. Indian J Microbiol. 2012; 53(2):495-9. doi: 10.1007/s12088-011-0226-y

4. Khoo HE, Azlan A, Tang ST, Lim SM. Anthocyanins; colored pigments as food, pharmaceutical ingredients and the potential health benefits. Food Nutri Res. 2017; 61:1361779. Doi:10.1080/16546628.2017.1361779

5. Turturica M, Qancea AM, Rapeanu G. Anthocyanins naturally occurring fruit pigments with functional properties. Food Technol. 2015; 39(1):9-24.

6. Renaud S, Gueguen R. The French paradox and wine drinking. Norvatis Found Symp. 1998; 216: 208-17. doi: 10.1002/9780470515549. ch13.

7. O'keefe JH, Bybee KA, Lavie CJ. Alcohol and cardiovascular health: The razor sharp double-edged sword. J Am Coll Cardiol. 2007; 50(11):1009-14. Doi: 10.1016/j.jacc.2007.04.089.

8. Freiberg MS, Samet JH. Alcohol and coronary heart disease: The answer awaits a randomized control trail. Circulation. 2005; 112(10):1379-81. Doi: 10.1161/CIRCULATIONAHA.105.568030.

9. Hansel B, Thomas F, Pannier B, Bean K, Kentush A, Chapman MJ, et al. Relationship between alcohol intake, health and social status and cardiovascular risk factors in the Urban Paris- lle-de-France Cohort; Is the cardioprotective action of alcohol a myth? Eur J Clin Nutr. 2010; 64:561-8. https://doi.org/10.1038/ejcn.2010.61

10. Cavallini G, Straniero S, Donati A, Bergamini E. Resveratrol requires red wine polyphenols for optimum antioxidant activity. $J$ Nutr Health Aging. 2016; 20:540-5. DOI: 10.1007/812603-150611-z.

11. 11. Fiore M, Laviola G, Aloe L, Fausto V, Mancineh R, Coccanti M. Early exposure of ethanol but not red wine at the same alcohol concentration induces behavioral and brain neotrophin alterations in young and adult mice. Neurotoxicology. 2009; 30(1):59-71. https:// doi.org/10.1016/j.neuro.2008.11.009.

12. Di-Castelnuovo A, Rotondo S, Lacoviello L, Donati MB., De Gaetano G. Meta-analysis of wine and beer consumption in relation to vascular risk. Circulation. 2002; 105(24):2836-44. Doi: 10.1161/01.cir.0000018653.19696.01.

13. Corrao G, Rubbiati L, Bagnardi V, Zambon A, Poikolamen C. Alcohol and coronary heart disease: A meta-analysis. Addiction. 2000; 95(10):1505-23. Doi: 10.1046/j.1360-0443.2000.951015056.x.

14. Maclure M. Demonstration of deductive meta-analysis: Ethanol intake and risk of myocardiac infarction. Epidemiol Rev. 1993; 15(2):328-51. Doi: 10.1093/oxfordjournals.epirev.a036124.

15. Lim SS, Von T, Flaxman AD, Danaei G, Shibuya K, Adair-Rohani H, et al. A comparative risk assessment of burden of diseases and injury attributable to 67 risk factors and risk factor clusters in 21 regions, 1990-2010: A systematic analysis for the Global Burden of Disease Study 2010. Lancet. 2012; 380(9859):2224-60. Doi: 10.1016/SO140-6736(12)61766-8.

16. Walorczyk S, Drodynski D, Gnusowski B. Multiresidue determination of 160 pesticides in wines employing mixed-mode dispersivesolid phase extraction and gas chromatography-tandem mass spectrometry. Talanta. 2011; 85(4):1856-1870. DOI: 10.1016/j. talanta.2011.07.029.

17. Tariba B. Metals in wine impact on wine quality and health outcomes. Biol Trace Elem Res. 2011; 144(1-3):143-56. DOI: 10.1007/ s12011-011-9052-7.

18. Magrone T, Jirillo E. Potential application of dietary polyphenols from red wine to attaining healthy ageing. Curr Top Med Chem. 2011; 11(14):1780-1796. doi: 102174/156802611796235116

19. Rodrigo R, Miranda A, Vergara L. Modulation of endogenous antioxidant system by wine polyphenols in human disease. Clin Chim Acta. 2011; 412(5-6):410-24. Doi: 10.1016/j.cca.2010.11.034.

20. Oczkowski M, Srednicka-Tober D, Stachon M, Kolota A, Wolinska-Witort E, Malik A, et al. The effect of red wine consumption on hormonal reproductive parameters and total antioxidant status in young adult male rats. Food Funct. 2014; 5(9):2096-105. https://doi. org/10.1039/C4O00108G 
21. Golan R, Shelef I, Shemesh E, Henkin Y, Schwarzfuchs D, Gepner Y, et al. Effects of initiating moderate wine intake on abdominal adipose tissue in adults with type 2 diabetes: A 2-year randomized controlled trial. Public Health Nutri. 2017; 20:549-555. DOI: 10.1017/S1368980016002597

22. Gepner Y, Golan R, Harman-Boehm I, Henkin Y, Schwarzfuchs D, Shelef I, et al. Effects of initiating moderate alcohol intake on cardiometabolic risk in adults with type 2 diabetes: A 2 year randomized, controlled trial. Ann Intern Med. 2015; 163:569-79. Doi: 10.7326/M14-1650

23. Downer MK, Betoroia ML, Mukamal KJ, Rimm EB, Stampfer MJ. Change in alcohol intake in relation to weight change in a cohort of United States men with 24 years of follow-up. Obesity. 2017; 25:1988-1996. DOI: 10.1002/oby.21979

24. Maclnnis RJ, Hodge AM, Dixon HG, Peeters A, Johnson LE, English DR, et al. Predictors of increased body weight and weight circumference for middle-aged adults. Public Health Nutri. 2014; 17:1087-1097. DOI: 10.1017/S1368980013001031

25. Dumesnil C, Dauchet L, Ruidavets JB, Bingham A, Arveiler D, Ferrieres J, et al. Alcohol consumption patterns and body weight. Ann Nutr Metab. 2013; 62:91-7. Doi: 10.1159/000342839

26. Drobinis EZ, Johnson M. The question of sperm DNA fragmentation testing in the male infertility work-up: A response to Professor Lewis' commentary. Reprod Biomed Online. 2015; 31:138-39. doi: 10.1016/j.rbmo.2015.05.004

27. Whitfield M, Pollet-Villard X, Levy R, Drevet JR, Saez F. Post-testicular sperm maturation, infertility and hypercholesterolemia. Asian $J$ Androl. 2015; 17(5):742-8. Doi: 10.4103/1008-682X.155536.

28. Katib A. Mechanisms linking obesity to male infertility. Cent European J Urol. 2015; 68(1):79-85. Doi: 10.5173/ceju.2015.01.435.

29. Esmaeilzadeh S, Andarieh MG, Ghadimi R, Delavar MA. Body mass index and gonadotropin hormones (LH \& FSH) associate with clinical symptoms among women with polycystic ovary syndrome. Glob J Health Sci. 2014; 7(2):101-6. Doi: 10.5539/gjhs.v7n2p101

30. Ranawat P, Khanduja KL, Pathak CM. Resveratrol-an ingredient of red wine abrogates the reproductive capacity in male mice. Andrologia. 2014; 46(6):650-8 DOI: 10.1111/and.12132.

31. Pavlidou E, Mantzorou M, Fasoulas A, Tryfonos C, Petridis D, Giaginis C. Wine: An aspiring agent in promoting longevity and preventing chronic diseases. Diseases. 2018; 6(3):73. DOI: 10.3390/diseases6030073

32. Sayon-Orea C, Bes-Rastrollo M, Nunez-Corboda JM, Basterra-Gortari FJ, Beunza JJ, Martinez-Gonzalez MA. Type of alcoholic beverage and incidence of overweight/obesity in a Mediterranean cohort: The SUN project. Nutr. 2011; 27:802-8. DOI: 10.1016/j. nut.2010.08.023

33. French MT, Norton EC, Fang H. Alcohol consumption and body weight. Health Econ. 2010; 19:814-32. DOI: 10.1002/hec.1521

34. Traversy G, Chaput J. Alcohol consumption and obesity: An update. Curr Obes Rep. 2015; 4(1):122-130. DOI: 10.1007/s13679-0140129-4.

35. Monteiro R., Soares R., Guerreiro S., Pestana D., Calhau C., Azevedo I. Red wine increases adipose tissue aromatase expression and regulates body weight and adipocytes size. J Nutr Biochem. 2009; 25(6):699-705. Doi: 10.1016/j.nut.2009.01.001.

36. Bargallo MV, Grau AA, Fernandez-Larrea, JD, Anguiano GP, Segerra MC, Rovira MJ, et al. Moderate red wine consumption partially prevents body weight gain in rats fed a hyperlipidic diet. J Nutr Biochem. 2006; 17(2):139-42. https://doi.org/10.1016/j. nutbio.2005.06.005.

37. Fernandes I, Perez-Gregorio R, Soares S, Mateus N, de Freitas V. Wine flavonoids in health and disease prevention. Molecules. 2007; 22:292. DOI: 103390/molecules22020292.

38. Cains S, Blomeley C, Burdakov D. Agrp neuron activity is required for alcohol-induced overeating. Nat Commun. 2017 ; 8:14014. https://doi.org/10.1038/ncomms14014.

39. Isaac UE, Akpuaka FC, Ndukwe GU. The effect of intake of palm wine on body weight and testicular microarchitecture in adult wistar rats. J Exp Clin Anat. 2017; 16(1):12-7. Available: https://www.jecajournal.org/text.asp?2017/16/1/12/212635. [Accessed 2020 Dec. 8].

40. Buemann B, Toubro S, Astrup A. The effect of wine or beer versus a carbonated soft drink, served at a meal, on ad libitum energy intake. Int J. Obes Relat Metab Disord. 2002; 26(10): 1367-72. Doi: 10.1038/sj.ijo.0802069. 